\title{
Data assimilation with dispersive tsunami model: a test for the Nankai Trough
}

\author{
Yuchen Wang ${ }^{1,2^{*}}$, Kenji Satake ${ }^{1}$, Takuto Maeda ${ }^{1,3}$ and Aditya Riadi Gusman ${ }^{1,4}$
}

\begin{abstract}
We present a method of tsunami data assimilation using a linear dispersive model in order to provide an accurate tsunami early warning. To speed up the assimilation process, we use the Green's function-based tsunami data assimilation, in which the Green's functions are calculated in advance with linear dispersive tsunami propagation models. We demonstrate a test case in the Nankai Trough off southwest Japan, with a source model similar to the main shock of the 2004 off the Kii Peninsula earthquake (M7.4) which generated tsunamis with dispersive characteristics. We show that assimilation of existing ocean bottom pressure gauge data can rapidly forecast the tsunami arrival time and the maximum height of the first tsunami peak along the coast of Shikoku and Kyushu Islands. Both the linear long-wave model and the linear dispersive model can accurately forecast the tsunami height, but the linear dispersive model can predict the tsunami arrival time more accurately for the tested earthquake.
\end{abstract}

Keywords: Tsunami forecasting, Data assimilation, Linear dispersive model, Linear long-wave model

\section{Introduction}

Tsunami data assimilation is a promising approach for tsunami forecasting. It predicts the tsunami waveform by assimilating offshore observed data into a numerical simulation, without calculating the initial sea surface height at the source (Maeda et al. 2015). An optimum interpolation method (Kalnay 2003) is adopted in data assimilation to compute the tsunami wavefield and to forecast the tsunami arrival time and maximum amplitude along the coast. This method has been successfully applied to observed tsunami waveforms of the 2012 Haida Gwaii Earthquake (Gusman et al. 2016) using bottom pressure gauge array data in the Cascadia subduction zone and a hypothetic tsunami in the Tohoku region (Maeda et al. 2015) using synthetic data based on the Seafloor Observation Network for Earthquakes and Tsunamis (S-net). If the observations are located in source regions, a new assimilation method developed by Tanioka (2018) can be used to solve the problem of non-hydrostatic effects and reproduce tsunami height distribution accurately.

*Correspondence: ywang@eri.u-tokyo.ac.jp

${ }^{1}$ Earthquake Research Institute, The University of Tokyo, Tokyo, Japan

Full list of author information is available at the end of the article
In previous applications of the tsunami data assimilation method, the linear long-wave (LLW) tsunami propagation model was used (Maeda et al. 2015; Gusman et al. 2016; Wang et al. 2017). The LLW model is based on the long-wave approximation (Satake 2015). When the horizontal scale of motion, or the wavelength of the tsunami, is much larger than the water depth, the vertical acceleration of water is negligible compared with gravity. The horizontal motion of the water mass is a good approximation uniform from the ocean bottom to the surface. Then, the phase velocity only depends on the depth of the ocean.

However, the long-wave approximation breaks down when the wavelength of the water height distribution is not much greater than the water depth (Saito et al. 2010). For example, if an outer-rise earthquake fault has a large dip angle, the initial sea surface distribution will be enriched in short-wavelength components, which could not be simulated properly with the LLW model (Saito and Furumura 2009; Zhou et al. 2012). Moreover, landside tsunamis have smaller horizontal scales than tsunamis generated by earthquakes, and they present more evident dispersion effects (Marchenko et al. 2012). The LLW model may forecast the arrival time of a tsunami peak to be earlier than the real tsunami and may overestimate the 
maximum height of the tsunami waveform (Watada et al. 2014; Gusman et al. 2015; Ho et al. 2017). Therefore, a dispersive (DSP) tsunami model based on the Boussinesq equations should be used to compute tsunami waveforms with dispersive characteristics. The DSP tsunami model has been successfully used in forward tsunami simulation (Furumura and Saito 2009; Zhou et al. 2012) and tsunami waveform inversion analysis to estimate the initial water height distribution (Saito et al. 2010, 2011).

Until now, there has been no application of the DSP model in tsunami data assimilation. Because the tsunami data assimilation method proposed by Maeda et al. (2015) calculates the wavefield at every time step, an application of the DSP model with this method would lead to an extremely high computational cost and therefore fail to provide timely tsunami early warnings. To speed up the data assimilation process, Green's functionbased tsunami data assimilation (GFTDA) was proposed to reduce the computational time for tsunami early warning (Wang et al. 2017). The Green's functions for data assimilation can be calculated and stored in advance. During the assimilation process, the waveforms at points of interest (PoIs) can be calculated by a simple matrix manipulation. The GFTDA enables us to conduct tsunami data assimilation with a linear dispersive model.

Great earthquakes have recurred along the megathrust fault between the Philippine Sea Plate and the Eurasian Plate along the Nankai Trough (Saito et al. 2010; Furumura et al. 2011). Such great earthquakes of recent years include the 1946 Tonankai (M7.9) and 1944 Nankai (M8.0) earthquakes. In addition, a large (M 7.4) earthquake occurred off the Kii Peninsula within the subducting Philippine Sea Plate in 2004. The tsunami generated by the 2004 off the Kii Peninsula earthquake exhibited evident dispersion characteristics at offshore stations such as MPG1 and MPG2 (Saito et al. 2010). One of the important features of tsunami generation is that the dispersive waves have a strong directional dependence with respect to the fault strike (Saito et al. 2010). Therefore, the dispersive tsunami developed efficiently toward the direction of the above offshore stations.

In order to monitor the earthquakes and tsunamis in the Nankai region, Japan Agency for Marine-Earth Science and Technology (JAMSTEC) set up the Dense Oceanfloor Network System for Earthquakes and Tsunamis (DONET). It is an elaborate system of cables and various devices and consists of 52 observation points in DONET1 and DONET2 (Kaneda 2010). Such a dense observation network enables us to forecast a tsunami along the Nankai coast by the method of tsunami data assimilation.

In this paper, we propose to use GFTDA to forecast the tsunami based on the linear DSP model. We compute synthetic tsunami observations in the Nankai region using the source parameters of the 2004 earthquake and forecast the tsunami along the coast of Shikoku Island and Kyushu Island. We also compare the forecasted results of arrival time and maximum height by assimilation using the LLW and DSP models.

\section{Methodology \\ Linear DSP tsunami model}

Numerical simulations of 2-D DSP tsunami equations have been conducted on high-performance computers and personal computers to simulate dispersive tsunami waves (Saito et al. 2010). The equations are derived from the continuity equation and the equation of motion for water waves. In Cartesian coordinate, they are:

$$
\begin{aligned}
& \frac{\partial h}{\partial t}=-\frac{\partial M}{\partial x}-\frac{\partial N}{\partial y}, \\
& \frac{\partial M}{\partial t}+g d \frac{\partial h}{\partial x}=\frac{1}{3} h^{2} \frac{\partial^{2}}{\partial x \partial t}\left(\frac{\partial M}{\partial x}+\frac{\partial N}{\partial y}\right), \\
& \frac{\partial N}{\partial t}+g d \frac{\partial h}{\partial y}=\frac{1}{3} h^{2} \frac{\partial^{2}}{\partial y \partial t}\left(\frac{\partial M}{\partial x}+\frac{\partial N}{\partial y}\right),
\end{aligned}
$$

where $M$ and $N$ are the $x$ and $y$ components of flux, or velocity integrated along the vertical direction from the sea bottom to the sea surface, $h$ is the tsunami height at the sea surface, $d$ is the water depth, and $g$ is the gravitational acceleration.

The right-hand sides of the second and third equations are linear dispersive terms, which cause the dispersion effect (Saito and Furumura 2009; Saito et al. 2010; Maeda et al. 2016). In the LLW model, we neglect the dispersion terms, so the right-hand sides of these two equations become zero. Although the linear DSP model is more complicated, the linearity still enables us to use GFTDA in our research.

\section{Optimal interpolation method}

We adopt the optimal interpolation method for tsunami data assimilation, as in the previous studies of Kalnay (2003) and Maeda et al. (2015). The details of the method are described in these two papers. In this method, we assume the total number of computational grid points is $L$, and the total observation number is $m$. The tsunami wavefield at the $n$th time step is represented as a $(3 L \times 1)$ column vector $\boldsymbol{x}_{\boldsymbol{n}}=(h(n \Delta t, x, y), M(n \Delta t, x, y), N(n \Delta t, x, y))^{\mathrm{T}}$.

The data assimilation process consists of two steps: a propagation step and an assimilation step. The propagation step is expressed as

$$
\boldsymbol{x}_{n}^{\mathrm{f}}=\boldsymbol{F} \boldsymbol{x}_{n-1}^{a},
$$


which means that at every time step, the forecasted tsunami wavefield $\boldsymbol{x}_{n}^{\mathrm{f}}$ is simulated by solving the tsunami propagation equations using the assimilated wavefield in the last time step $\boldsymbol{x}_{n-1}^{a}$. Here, $\boldsymbol{F}$ refers to the tsunami propagation matrix $(3 L \times 3 L)$ that corresponds to the tsunami propagation model. The assimilation step is expressed as

$$
\boldsymbol{x}_{n}^{a}=\boldsymbol{x}_{n}^{\mathrm{f}}+\boldsymbol{W}\left(\boldsymbol{y}_{n}-\boldsymbol{H} \boldsymbol{x}_{n}^{\mathrm{f}}\right),
$$

where the observation matrix $\boldsymbol{H}(m \times 3 L)$ is a sparse matrix that extracts the forecasted tsunami heights at the $m$ points from the entire simulated tsunami wavefield. The residual is calculated by comparing it with the real observed tsunami height $\boldsymbol{y}_{n}$. The weight matrix $\boldsymbol{W}$ $(3 L \times m)$ is an important controlling factor for the quality of tsunami assimilation (Maeda et al. 2015). It is calculated by minimizing the covariance matrix as a solution of the linear system

$$
\boldsymbol{W}\left(\boldsymbol{R}+\boldsymbol{H} \boldsymbol{P}^{\mathrm{f}} \boldsymbol{H}^{\mathrm{T}}\right)=\boldsymbol{P}^{\mathrm{f}} \boldsymbol{H}^{\mathrm{T}},
$$

where $\boldsymbol{P}^{\mathrm{f}}=\left\langle\varepsilon^{\mathrm{f}} \varepsilon^{\mathrm{fT}}\right\rangle$ and $\boldsymbol{R}=\left\langle\varepsilon^{\mathrm{O}}{ }_{\varepsilon} \mathrm{OT}\right\rangle$ are the covariance

matrices of the forward numerical simulation and the observations, respectively. Here, $\varepsilon^{f}$ represents the errors in numerical forecasts between two computational grids and $\varepsilon^{\mathrm{O}}$ represents the observational errors (Kalnay 2003; Maeda et al. 2015). The weight matrix is then multiplied by the residual to bring the assimilated tsunami wavefield closer to the observed wavefield. By alternatively repeating the propagation and assimilation steps, the tsunami wavefield is assimilated.

\section{Green's function-based tsunami data assimilation (GFTDA)}

In order to speed up the data assimilation process and use the linear DSP model, we use the GFTDA proposed by Wang et al. (2017). The Green's function $G_{i, j}$ is defined as the waveform at the $j$ th grid point resulting from the propagation of the $i$ th station's assimilation response. We compute the Green's functions between the fixed observation stations and PoIs with both the LLW model and the linear DSP model. The computation of Green's functions might be quite time-consuming, but this is done in advance. Moreover, this will not affect the efficiency of the data assimilation process. Then, during the assimilation process, we can directly synthesize the forecasted tsunami waveforms by multiplying the residual by the corresponding Green's functions.

\section{Green's function}

The bathymetry and topography dataset are derived from the General Bathymetric Chart of the Ocean (GEBCO). The grid data released in 2014 (GEBCO_2014) with a grid spacing of 30 arc s (Weatherall et al. 2015) are used.

The finite difference method (FDM) with the implicit scheme is used for numerical simulation. We use a grid spacing of $30 \mathrm{arc} s$ and a time step of $1 \mathrm{~s}$. The target area is $30^{\circ} \mathrm{N}-35^{\circ} \mathrm{N}, 130^{\circ} \mathrm{E}-140^{\circ} \mathrm{E}$, so the total grid number is $600 \times 1200=720,000$.

The JAGURS tsunami code (Baba et al. 2015) is used to compute the Green's functions between the observation points and PoIs and also between different observation points. We use 15 observation stations and nine PoIs, as described in the next section. Hence, the total number of Green's functions is $15 \times(9+15)=360$. The parameters for optimal interpolation are similar as those used in a study by Maeda et al. (2015).

\section{Application and results \\ Observation stations and forecast points}

We used the proposed method to simulated data for the Nankai Trough. DONET has 13 science nodes, and each node is linked with several bottom pressure observation points. In order to build an evenly distributed observation network for data assimilation, we take one point for each node except for Node $\mathrm{C}$, for which we take two observation points. In addition, we use the submarine cable stations PG1 and PG2, also maintained by JAMSTEC. In total, 15 observation stations are used for data assimilation (Fig. 1). However, because DONET1 was completed in 2011 and DONET2 started operation in 2015, we lack a real tsunami record for the 2004 off the Kii Peninsula earthquake. To assess the ability of our data assimilation approach, we use synthetic tsunami data from the 2004 earthquake source model. In real practice, tsunami data could be obtained by removing the tide signal and high-frequency seismic signal from the observation record. The method of Tanioka (2018) can also be applied to the stations in or around the source area.

The nine points of interest (PoIs) are selected near population centers on the coast of Shikoku Island and Kyushu Island (Fig. 1), which are under the potential threat of tsunami disaster. They are used to compare simulated waveforms and waveforms predicted by data assimilation.

\section{Source models}

In our numerical simulation, we use the mainshock source model of the 2004 off the Kii Peninsula earthquake. The fault parameters are set according to the unpublished results of Yamanaka (data available at http:// 


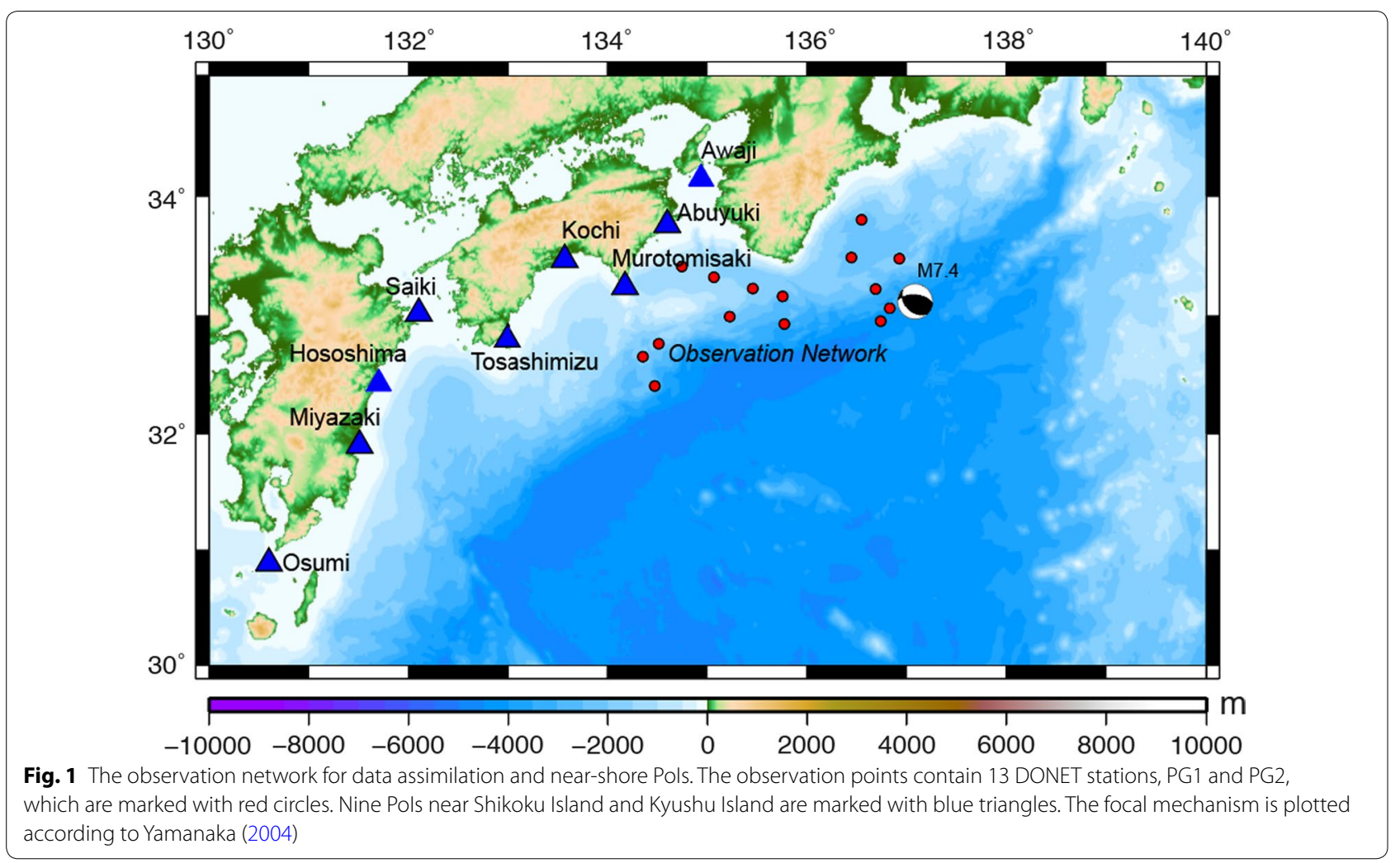

wwweic.eri.u-tokyo.ac.jp/sanchu/Seismo_Note/2004/ EIC153.html) by analysis of the teleseismic body waves. The epicenter is $137.142^{\circ} \mathrm{E}, 33.143^{\circ} \mathrm{N}$, and the depth is $10.0 \mathrm{~km}$. The fault direction is perpendicular to the trough axis with a strike of $135^{\circ}$. The dip angle is $40^{\circ}$, and the rake angle is $123^{\circ}$. The length and width of the rectangular fault are $50.0 \mathrm{~km}$ and $30.0 \mathrm{~km}$, respectively. The fault slip is $6.5 \mathrm{~m}$, which is consistent with the magnitude of the main shock (M7.4).

We use Okada's model to calculate the initial sea surface elevation in an elastic half-space (Okada 1985), which can be used as the initial condition for numerical simulation. Here, we only consider the vertical displacement. If the tsunami source is on a steep seafloor and the horizontal motion is much larger than the vertical motion, horizontal displacement will become important for tsunami generation (Tanioka and Satake 1996).

\section{Assimilation setting}

We use the JAGURS tsunami code to calculate the tsunami propagation. We consider only linear terms and assume reflective boundary at the coastline. To make the tsunami propagation closer to the real situation, we apply the linear DSP model, similar to that used to compute the dispersive Green's functions.
We set the earthquake origin time as $t=0$. The observation stations of the assimilation network are not far from the epicenter of the Kii Peninsula earthquakes. Hence, the tsunami arrives at the nearby stations of KMC09, KMC21, and KMD13 soon after the earthquake (Fig. 2). We set that the data assimilation process to begin at $t=0$. The assimilation time window is defined as the period during which we use synthetic observation for assimilation. During the assimilation time window, the waveforms at PoIs are synthesized with the Green's functions and the simulated observation.

We apply the GFTDA algorithm with both the LLW and linear DSP models. The length of the time windows is set to range from 2 to $24 \mathrm{~min}$, with an interval of $2 \mathrm{~min}$. The calculation time for the data assimilation process is less than $10 \mathrm{~s}$, almost negligible on the EIC computer system at the Earthquake Research Institute, the University of Tokyo.

\section{Waveform comparison}

Figure 3 demonstrates the comparison between simulated waveforms and waveforms predicted with an assimilation time window of $20 \mathrm{~min}$. The waveforms predicted using both the LLW model and the linear DSP model agree well with the simulated waveforms. This proves the validity of data assimilation based on the observation 

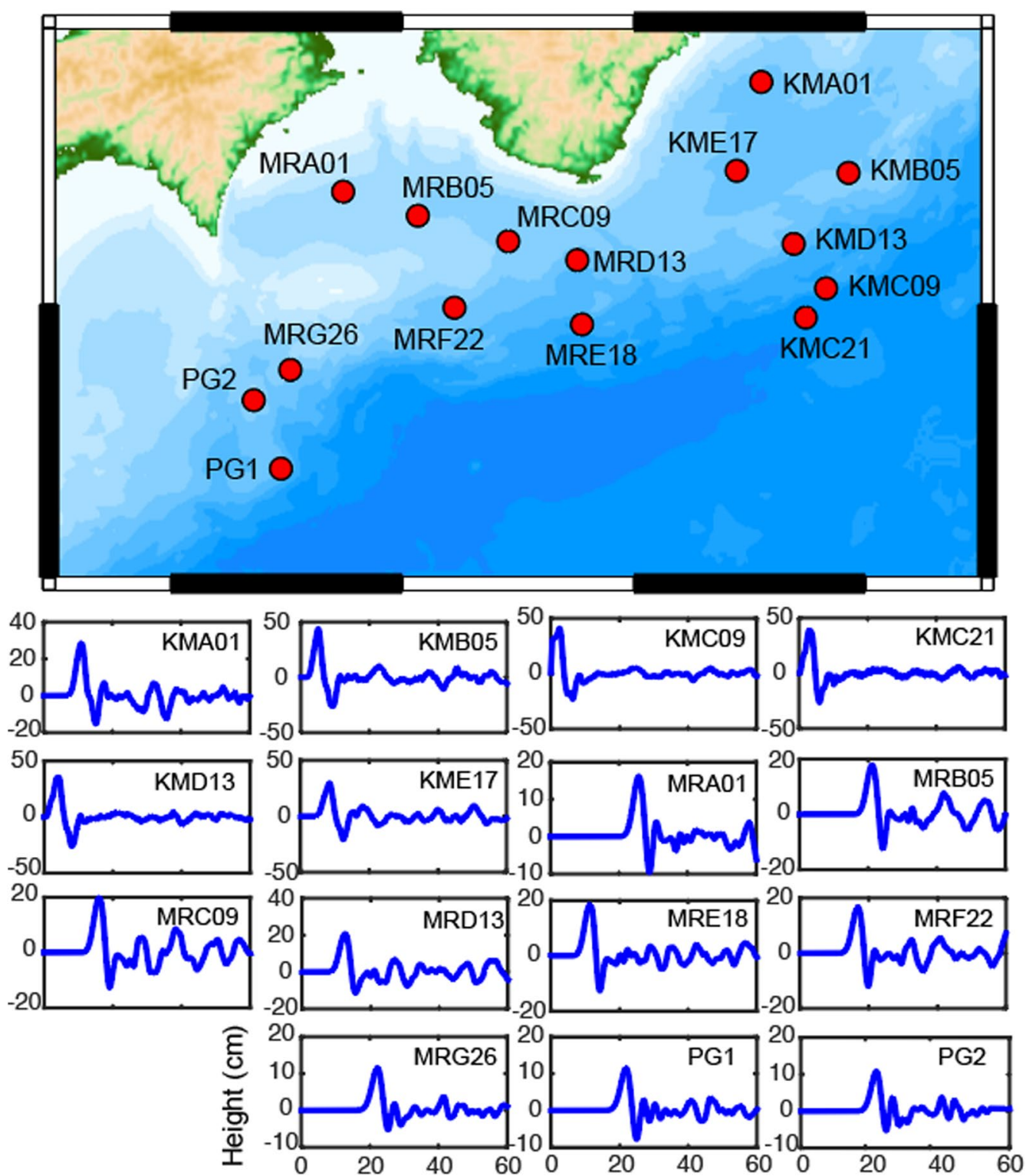

Time after Earthquake (min)

Fig. 2 Distribution of 15 observation points and the waveforms of synthetic tsunamis at each point. The tsunami arrives at the stations of KMC09, KMC21, and KMD13 soon after the earthquake. The data assimilation process begins at the time of earthquake

network of DONET, PG1 and PG2. For the forecasting the first tsunami peak amplitude, the LLW model and the linear DSP model have similar performances. In the coastal PoIs of Murotomisaki, Awaji, and Abuyuki, the maximum amplitude forecasted by the linear DSP model tends to be closer to the simulation than that forecasted by the LLW model, though the differences are quite small. The main difference between the two models lies in the arrival time. In almost every PoI, especially Tosashimizu and Murotomisaki, the predicted waveform using the linear DSP model has a more accurate arrival time of the first tsunami peak.

\section{Quantitative evaluation}

To quantitatively evaluate the performance of two models in data assimilation, we calculate the tsunami forecast accuracy (Gusman et al. 2016) for different assimilation time windows. It is based on the geometric mean ratio $(K)$ of the observed $\left(O_{i}\right)$ and simulated $\left(S_{i}\right)$ maximum 

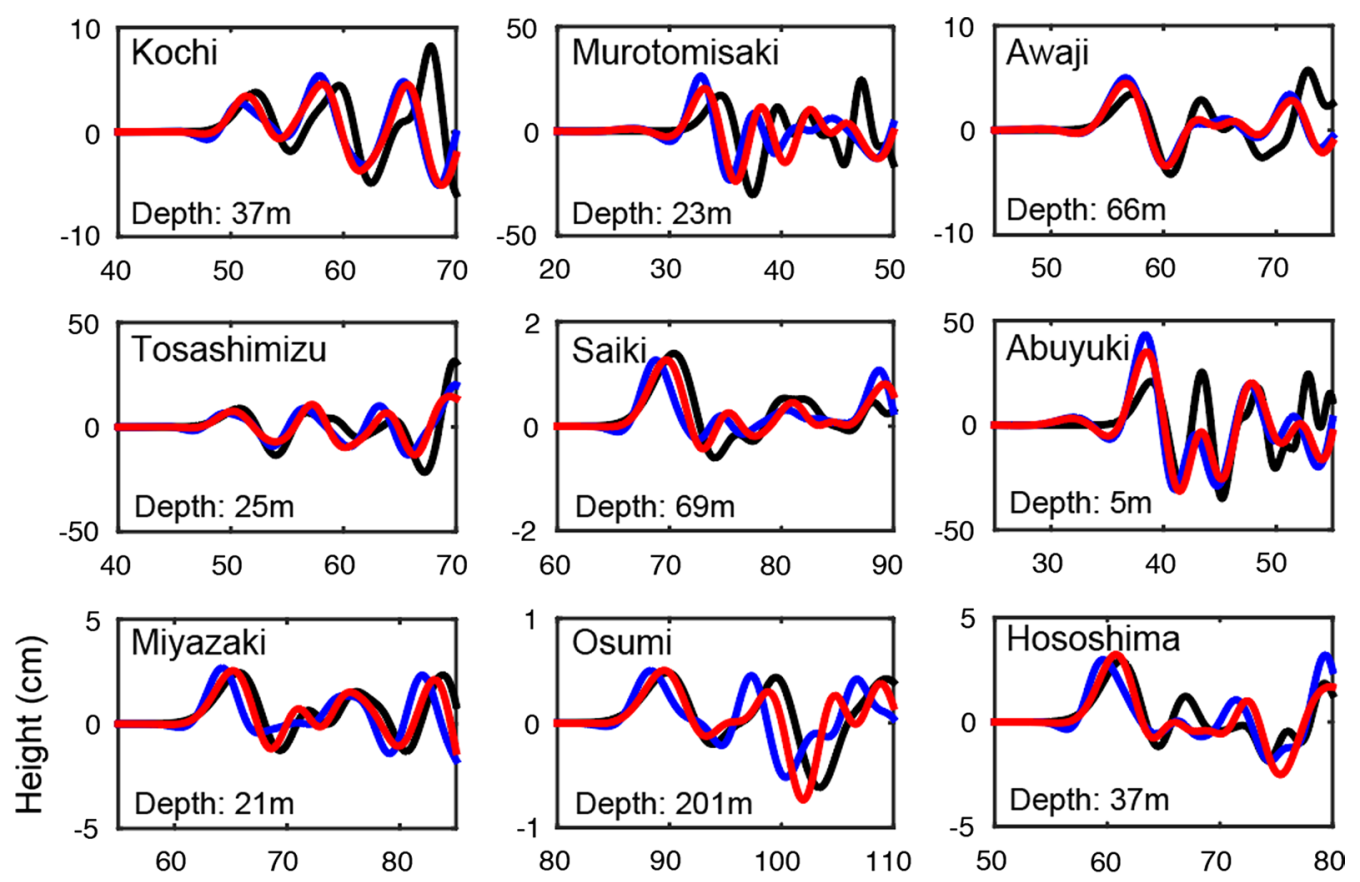

Time after Earthquake (min)

\section{Observation}

\section{Assimilation (LLW) Assimilation (DSP)}

Fig. 3 Simulated waveforms (black lines) and waveforms forecasted by data assimilation at nine near-shore Pols. The water depth of each Pol is provided. The forecasted waveforms are calculated by GFTDA using the LLW model (blue lines) and the linear DSP model (red lines). The time window of data assimilation is $20 \mathrm{~min}$

amplitude of the first tsunami peak for the $i$ th station (Aida 1978),

$$
\begin{aligned}
& \log (K)=\frac{1}{N} \sum_{i=1}^{N} \log \left(\frac{O_{i}}{S_{i}}\right), \\
& \text { Accuracy (\%) }=\frac{1}{K} \times 100 \%(K \geq 1) \text { or } K \times 100 \%(K<1),
\end{aligned}
$$

where $N$ is the number of stations. Generally, a high accuracy value could indicate accurate forecasting of the tsunami data assimilation.

The accuracy for various assimilation time windows is plotted in Fig. 4a. The shapes of the forecasting accuracy curves for both the LLW model and the linear DSP model are quite similar. In the beginning, the time window is only $2 \mathrm{~min}$, and soon after the earthquake, the accuracy of both models is very low. Because the first tsunami peak has not passed through any observation stations of our network, the data length used for assimilation is too short to provide accurate forecasts. Then, at $4 \mathrm{~min}$, there is a sharp increase in the accuracy for both models, with the forecast accuracy exceeding 85\% (Fig. 4). After that, the forecast accuracy varies slightly but exhibits a rising trend in general. Although there is not a large difference in forecast accuracy between the LLW model and the linear DSP model, the forecast accuracy of the LLW model is slightly higher. After the time window of $20 \mathrm{~min}$, the first tsunami peak has already passed all of the observation stations. The forecast accuracy becomes saturated and stops increasing. Here, the values of forecasting accuracy calculated by both models are also similar, but the linear DSP model performs slightly better.

The difference in arrival time of the first tsunami peak between the two models is more evident. To quantitatively analyze the accuracy of the forecasted arrival time, we use the method of calculating time lag proposed by Tsushima et al. (2012). The time lag of the $i$ th coastal station is defined as:

$$
\Delta T_{i}=t_{i}^{S}-t_{i}^{O}
$$



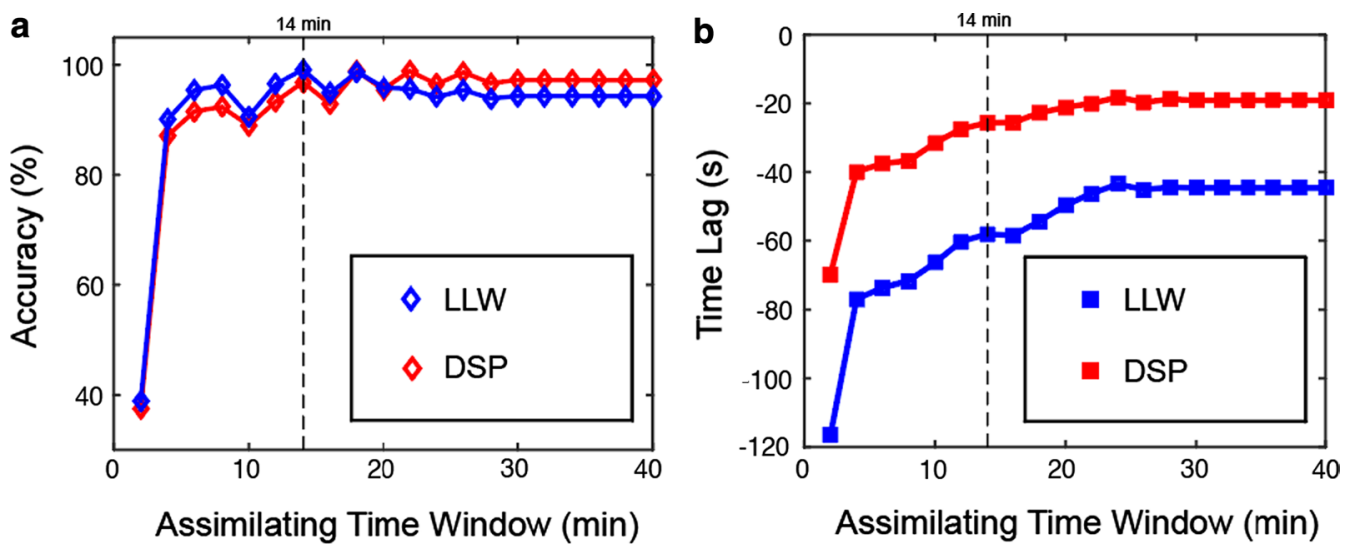

Fig. 4 Forecast accuracy $\mathbf{a}$ and time lag $\mathbf{b}$ of the two models for various assimilation time windows. The forecast accuracy is used to evaluate the forecasted maximum amplitude of the first tsunami peak (Aida 1978). The time lag is used to examine the forecasted arrival time (Tsushima et al. 2012)

where $t_{i}^{O}$ is the arrival time of the first tsunami peak observed at the $i$ th station and $t_{i}^{S}$ is the arrival time forecasted by data assimilation. A negative time lag indicates that the forecasted arrival time is earlier than the observation. A small absolute value of time lag indicates accurate forecasting of the arrival time. We calculate the time lag at all PoIs and calculate the average value.

Figure $4 \mathrm{~b}$ clearly shows that the time lags calculated by the two models are clearly negative, which means that both the LLW model and the linear DSP model forecast the tsunami arrival times earlier than observed. Moreover, as the assimilation time window increases, the time lag becomes closer to zero. The tendency of the variation of time lag is the same as that of forecasting accuracy. As more observed data are used in data assimilation, the absolute value of time lag decreases quickly from the end of the 2-min time window to the 4-min time window. Then, it decreases slowly. After the time window of $20 \mathrm{~min}$, the variation finally becomes very small. It is important to note that the difference between the LLW model and the linear DSP model is noticeable in the figure. The linear DSP model leads to a much smaller time lag than the LLW model, indicating that the linear DSP model performs better in forecasting tsunami arrival time.

\section{Discussion and conclusion}

In our application, we use two linear models, the LLW model and the linear DSP model. The accuracy of the forecasted maximum amplitude and arrival time depends on the length of the assimilation time window. It is important to choose a proper assimilation time window for both models. In our application to the 2004 off the Kii Peninsula earthquake, a time window of $14 \mathrm{~min}$ is a practical choice in order to produce a reliable and early tsunami forecast. At this time, the forecast accuracy of both the LLW and linear DSP models exceeds $96 \%$, and the average time lag of tsunami arrival time is $-58.1 \mathrm{~s}$ (LLW) and $-25.7 \mathrm{~s}$ (DSP). Figure 2 shows that the first tsunami peak reaches the nearest PoI (Murotomisaki) around $35 \mathrm{~min}$ after the earthquake and reaches other PoIs more than $40 \mathrm{~min}$ after the earthquake. Using the tsunami height and arrival time of PoIs as input parameters, the shoreline tsunami height or inundation forecasts will be possible by applying the tsunami run-up models (Liu et al. 2009).

Because the calculation time in the GFTDA process is negligible, the tsunami forecast can be made $14 \mathrm{~min}$ after the earthquake based on the data assimilation. On the other hand, it is not practical to use a time window of more than $20 \mathrm{~min}$. Though the forecasting accuracy becomes even higher and the time lag becomes even smaller, the tsunami forecast may not be useful if it is made shortly before the tsunami arrival.

The results also suggest that the tsunami propagation model could affect the accuracy of tsunami forecasting by data assimilation. For the maximum amplitude of the first tsunami peak, two models perform similarly. However, with respect to the arrival time, the linear DSP model has a better accuracy than the LLW model. The average time lag calculated by the linear DSP model is evidently smaller. For individual stations, if the station is located near Shikoku Island, which is close to the observation network, the difference in lag time is not so large. However, if the station is located near Kyushu Island which is approximately $200 \mathrm{~km}$ from the observation network, the difference in lag time becomes noticeable. This is caused by the limitation 
of the long-wave approximation. The limitations of the long-wave approximation may not be so evident when the wavelength of tsunami is sufficiently long. However, for the Kii Peninsula earthquake considered in this paper, the large dip results in short-wavelength components of the tsunami, and such an approximation would overestimate the velocity of tsunami propagation (Saito et al. 2010). Thus, the arrival time forecasted by the LLW model becomes quite earlier than the DSP model results, especially for PoIs far from the observation network, because a longer propagation distance will increase such errors.

Compared with the previous data assimilation method, the simple assimilation process of GFTDA enables us to apply more complicated models, apart from the LLW model. As long as linearity is assumed, the GFTDA is proven to be mathematically equivalent to the previous data assimilation approach (Wang et al. 2017). For potential tsunamis with more dispersion characteristics, or tsunamis that propagate over a longer distance from the observation network, the difference between dispersive and non-dispersive models is more important. Therefore, the linear DSP model would be able to make more improvements in forecasting the arrival time accurately and to mitigate the disasters of potential destructive tsunamis generated by outer-rise earthquakes.

\section{Abbreviations \\ DSP: dispersive; DONET: Dense Oceanfloor Network System for Earthquakes and Tsunamis; EIC: Earthquake Information Center; FDM: finite difference method; GFTDA: Green's function-based tsunami data assimilation; JAM- STEC: Japan Agency for Marine-Earth Science and Technology; LLW: linear long-wave; Pol: point of interest; S-net: Seafloor Observation Network for Earthquakes and Tsunamis.}

\section{Authors' contributions}

YW conducted GFTDA and analyzed the different performance of two models. KS contributed to the tsunami propagation model. TM and AG contributed to the tsunami data assimilation code. All authors read and approved the final manuscript.

\section{Author details \\ ${ }^{1}$ Earthquake Research Institute, The University of Tokyo, Tokyo, Japan. ${ }^{2}$ Department of Earth and Planetary Science, Graduate School of Science, The University of Tokyo, Tokyo, Japan. ${ }^{3}$ Graduate School of Science and Technol- ogy, Hirosaki University, Aomori, Japan. ${ }^{4}$ GNS Science, Lower Hutt 5040, New Zealand.}

\section{Acknowledgements}

We thank the General Bathymetric Chart of the Ocean (GEBCO) for the bathymetric data. We would also like to thank Prof. Takashi Furumura for his suggestions regarding the dispersive tsunami model. We used the JAGURS tsunami simulation code (Baba et al. 2015; available at https://github.com/ jagurs-admin/jagurs) and the TDAC data assimilation code (Maeda et al. 2015; Gusman et al. 2016; Wang et al. 2017; available at https://github.com/takut o-maeda/tdac).

\section{Competing interests}

The authors declare that they have no competing interests.

\section{Availability of data and materials}

The TDAC code for tsunami data assimilation (Maeda et al. 2015; Gusman et al. 2016; Wang et al. 2017) is available at https://github.com/takuto-maeda/tdac. The JAGURS code for computing Green's functions and synthetic tsunami (Baba et al. 2015) is available at https://github.com/jagurs-admin/jagurs.

\section{Consent for publication}

Not applicable.

Ethics approval and consent to participate Not applicable.

\section{Funding}

This work was partially supported by KAKENHI $16 \mathrm{H} 01838$ (K. Satake) and KAKENHI $15 K 16306$ (T. Maeda). Y. Wang thanks the Earthquake Research Institute for providing the funding for his Master's Program (Global Science Graduate Course).

\section{Publisher's Note}

Springer Nature remains neutral with regard to jurisdictional claims in published maps and institutional affiliations.

Received: 4 April 2018 Accepted: 6 August 2018

Published online: 13 August 2018

\section{References}

Aida I (1978) Reliability of a tsunami source model derived from fault parameter. J Phys Earth 26(1):57-73

Baba T, Takahashi N, Kaneda Y et al (2015) Parallel implementation of dispersive tsunami wave modeling with a nesting algorithm for the 2011 Tohoku tsunami. Pure Appl Geophys 172(12):3455-3472. https://doi.org/10.1007/ s00024-015-1049-2

Furumura T, Saito T (2009) Integrated ground motion and tsunami simulation for the 1944 Tonankai earthquake using high-performance supercomputers. J Disaster Res 4:118-126

Furumura T, Imai K, Maeda T (2011) A revised tsunami source model for the 1707 Hoei earthquake and simulation of tsunami inundation of Ryujin Lake, Kyushu, Japan. J Geophys Res 116:B02308. https://doi. org/10.1029/2010JB007918

Gusman AR, Murotani S, Satake K et al (2015) Fault slip distribution of the 2014 Iquique, Chile, earthquake estimated from ocean-wide tsunami waveforms and GPS data. Geophys Res Lett 42:1053-1060. https://doi. org/10.1002/2014GL062604

Gusman AR, Sheehan AF, Satake K et al (2016) Tsunami data assimilation of high-density offshore pressure gauges off Cascade from the 2012 Haida Gwaii earthquake. Geophys Res Lett 43(9):4189-4196. https://doi. org/10.1002/2016GL068368

Ho TC, Satake K, Watada S (2017) Improved phase corrections for transoceanic tsunami data in spatial and temporal source estimation: application to the 2011 Tohoku earthquake. J Geophys Res Solid Earth 122:1015510175. https://doi.org/10.1002/2017JB015070

Kalnay E (2003) Atmospheric modeling, data assimilation and predictability. Cambridge University Press, Cambridge

Kaneda Y (2010) The advanced ocean floor real time monitoring system for mega thrust earthquakes and tsunamis-application of DONET and DONET2 data to seismological research and disaster mitigation. OCEAN 2013. https://doi.org/10.1109/OCEANS.2010.5664309

Liu PLF, Wang X, Salisbury AJ (2009) Tsunami hazard and early warning system in South China Sea. J Asian Earth Sci 36:2-12. https://doi.org/10.1016/j. jseaes.2008.12.010

Maeda T, Obara K, Shinohara M et al (2015) Successive estimation of a tsunami wavefield without earthquake source data: a data assimilation approach toward real-time tsunami forecasting. Geophys Res Lett 42:7923-7932. https://doi.org/10.1002/2015GL065588

Maeda T, Tsushima H, Furumura T (2016) An effective absorbing boundary condition for linear long-wave and linear dispersive-wave tsunami simulations. Earth Planets Space 68:63. https://doi.org/10.1186/s4062 3-016-0436-y 
Marchenko AV, Morozov EG, Muzylev SV (2012) A tsunami wave recorded near a glacier front. Nat Hazard Earth Syst Sci 12:415-419. https://doi. org/10.5194/nhess-12-415-2012

Okada Y (1985) Surface deformation due to shear and tensile faults in a halfspace. Bull Seismol Soc Am 75(4):1135-1154

Saito T, Furumura T (2009) Three-dimensional simulation of tsunami generation and propagation: application to intraplate events. J Geophys Res 114:B02307. https://doi.org/10.1029/2007JB005523

Saito T, Satake K, Furumura T (2010) Tsunami waveform inversion including dispersive waves: the 2004 earthquake off Kii Peninsula, Japan. J Geophys Res 115:B06363. https://doi.org/10.1029/2009JB006884

Saito T, Ito Y, Inazu D, Hino R (2011) Tsunami source of the 2011 Tohoku-Oki earthquake, Japan: inversion analysis based on dispersive tsunami simulations. Geophys Res Lett 38:LO0G19. https://doi.org/10.1029/2011g 1049089

Satake K (2015) Tsunamis. In: Schubert G (ed) Treatise on geophysics, vol 4, 2nd edn. Elsevier, Oxford, pp 477-504

Tanioka Y (2018) Tsunami simulation method assimilating ocean bottom pressure data near a tsunami source region. Pure Appl Geophys 175:721-729. https://doi.org/10.1007/s00024-017-1697-5

Tanioka Y, Satake K (1996) Tsunami generation by horizontal displacement of ocean bottom. Geophys Res Lett 23:861-864. https://doi. org/10.1029/96GL00736
Tsushima H, Hino R, Tanioka Y et al (2012) Tsunami waveform inversion incorporating permanent seafloor deformation and its application to tsunami forecasting. J Geophys Res 117:B03311. https://doi.org/10.1029/2011 J B008877

Wang Y, Satake K, Maeda T, Gusman AR (2017) Green's function-based tsunami data assimilation (GFTDA): a fast data assimilation approach toward tsunami early warning. Geophys Res Lett 44:10282-10289. https://doi. org/10.1002/2017GL075307

Watada S, Kusumoto S, Satake K (2014) Traveltime delay and initial phase reversal of distant tsunamis coupled with the self-gravitating elastic Earth. J Geophys Res Solid Earth 119:4287-4310. https://doi.org/10.1002/2013J B010841

Weatherall P, Marks KM, Jakobsson M et al (2015) A new digital bathymetric model of the world's oceans. Earth Space Sci 2:331-345. https://doi. org/10.1002/2015EA000107

Yamanaka Y (2004) EIC seismology note. http://wwweic.eri.u-tokyo.ac.jp/sanch u/Seismo_Note/2004/ElC153.html. Accessed 22 Oct 2004

Zhou H, Wei Y, Titov W (2012) Dispersive modeling of the 2009 Samoa tsunami. Geophys Res Lett 39:L16603. https://doi.org/10.1029/2012GL0530

\section{Submit your manuscript to a SpringerOpen ${ }^{\circ}$ journal and benefit from:}

- Convenient online submission

- Rigorous peer review

- Open access: articles freely available online

- High visibility within the field

- Retaining the copyright to your article

Submit your next manuscript at $\boldsymbol{\nabla}$ springeropen.com 